\title{
Advantages and Disadvantages of Greek Universities: \\ Implications for science education
}

\section{Nicholas K. Spyrou}

\section{Introduction}

I S H A L L O U T L I N E briefly the present situation in Greek universities, their goals and characteristics, and the conditions under which, in my opinion, these goals can be accomplished. It is generally accepted that one of the main objectives of the university is the development of a close relationship with its social surroundings. Such a relation will promote the university's basic functions and contribute in a decisive way to solving the main problems of its social environment. This goal presents an enormous challenge. The struggle of universities for freedom of action and autonomy from official state power and other religious and social authorities, began almost simultaneously with the creation of the first foundations for the search of scientific truth and the organized dissemination of k1nowledge. This struggle already existed in antiquity, assuming that the schools of Plato, Aristotle, and the Stoic philosophers were the primitive forms of a university. Initially, conflicts emerged because new ideas and knowledge confronted older ideas and prejudices about the nature of the cosmos, matter, and life. The content of the confrontation gradually changed, moving towards the interaction and interdependence of the university with the official state, namely the government and political parties, and society. It is important that this interaction and interdependence be closely related without seriously affecting the quality of education, the cultivation of knowledge and culture, the creation of new ideas and notions, and research, either basic or applied. In a properly functioning parliamentary democracy, the balance of the above three factors, namely, the internal functioning of the university, politics and society, is imperative; the balance might not always be optimal, but it must permit and guarantee the main 
functions of the university, and at the same time promote the solution of social problems.

\section{Advantages and Disadvantages}

The main advantage of the Greek university is the good quality of its students and staff. This has been independently verified by the effectiveness and scientific productivity of many Greeks in foreign universities at various ranks and levels, and also by the high degree of collaboration between Greek and foreign universities, on a more or less equal basis, in various subjects and scientific areas-something that, undoubtedly, must be supported and expanded. Furthermore, in Greek universities there are no fees, and all printed material for educational purposes is normally given to students free of charge. Whether or not this is really an advantage for any educational system is under question. Also, today in Greece there are seventeen universities apart from the higher technological institutes.

The above advantages do not guarantee the proper functioning of Greek universities. There are also some serious disadvantages, including (1) the renewal of staff; (2) new staff; (3) relations between universities and the official state; (4) the budget and staff salaries; (5) evaluation of universities; (6) university governance; (7) the administrative system; (8) the establishment of private universities; and (9) university entrance examinations just to mention a few.

The confrontation of the disadvantages and the solution to the corresponding problems must be the content of an appropriate legislative framework, for which the official state is responsible, and the internal regulations, for which every university is responsible. As things appear now, the structure of the state legislative actions and terms is very complicated and extremely intricate, quite frequently paralyzing the university's general functioning. The combination of a simple legislative framework and internal regulations favors the selfgovernance of the university, and if necessary, permits rapid changes according to prevailing ideas, trends, problems, and interests in various periods. 


\section{Legislative Framework and Internal Regulations}

1. The renewal of the teaching and research staff is very difficult, if not impossible. No new staff positions are created and, consequently, the staff of various departments is aging with no successors in sight.

2. There are no more teaching and research assistants to aid professors in their teaching and gradually become experienced enough to succeed them in the future.

3. There is continuous interference from the State aimed at reforming, approximately every four years, the basic articles of the legislative framework for universities. It is an unfortunate tradition that every minister for education feels obliged to interfere and make changes. There are many traumatic examples of interference by the State in the functioning of Greek universities. From those examples it is deduced that before any legislative action concerning the university is taken, one must first recognize and enumerate with great caution the many details and parameters of the problem considered, and then properly treat them and discuss them with all interested parties, so as to guarantee the maximal effectiveness of the legislative action. All final decisions must be made in the best interests of the university, not of any political party.

4. The salaries of the university staff are very low compared with those of the rest of Europe and the United States. Furthermore, the budget must be increased and money must be used in a more flexible way without state interference. The budget, to the extent that it is specified by the ministry, must be made known to all universities early in the beginning of each academic year. Similarly, the program of public investments must be made known early and must be specific, taking into account the needs of each of the universities, especially the peripheral ones.

Closely related to the level of the yearly budget is the fact that in Greek universities there are no fees of any kind; education is free. Also, students receive all required printed material totally free, at a substantial cost. Moreover, students are not required to take prerequisite subjects and can transfer subjects from one semester to the next, thus resulting in an inconsistent acquisition of knowledge. Finally, 
they can have meals and transportation and partial accommodation at a reduced rate during the normal period of their studies.

In view of the above, educational (and not only educational) fees must be established, probably with financial exemptions based on educational, scientific and social criteria for the economically poorer students. Needless to say, a more effective use of the important property of the university is necessary.

5. There is no systematic evaluation of universities nor any comparison made between them. All universities are considered by the State on an equal basis, independently of their scientific productivity and their number of under- and postgraduate students. All universities should be evaluated in an objective and commonly accepted way, so that funding by the State can be linked to enrollment and productivity. It is clear that the comparison between universities will effect an analogous comparison of their graduates, a very important fact, indeed, related to their future work,

6. University governing bodies are numerous, so it is very difficult to reach decisions on especially important matters.

7. The administration must be modernized, made as efficient as possible, and become, either directly or indirectly, independent, so that teaching and research activities will not be adversely affected.

8. In Greece, all universities and technological institutes are state owned; only recently has the establishment of private universities been discussed. In order to consider whether private universities should be established in Greece, one has to take into account the number of graduates in each area and the emigration of students. More precisely, at each moment one has to know the exact number of graduates and monitor the level of unemployment of the graduates of various specialties. In this way, it will be possible to address the problem of excessive enrollment in some areas (e.g., in the schools of medicine).

Furthermore, the problem of the emigration of students, this bleeding wound of our country, is closely related to the possible establishment of private universities, and the clear framework in which they plan to function. The goal of stopping "the endless caravan" of Greek children to universities abroad must be considered as a national one for many reasons. This problem can be solved by, on the one hand, improving the state universities and technological institutes, through 
the creation of new directions of learning in the universities, and, on the other hand, by establishing new, private universities.

The positive or negative attitude toward private universities must not be the result of biased decisions. For example, many think that the problem is simple, and so they suggest drastic solutions. However, the problem deserves serious and systematic study. Thus there are many obstacles in the country's constitutional charter concerning the very existence of private universities, which could be overcome by simply revising the corresponding articles in the constitutional charter.

A few questions related to the very essence of the problem are these:

i. Will private universities be allowed to establish themselves in every place in the country (e.g., in large urban centers), or will they be used as a means for the educational, cultural, and technological development of small and peripheral cities?

ii. In which specific areas of knowledge will private universities be permitted to function?

iii. How will the State control private universities with regard to the quality of studies offered to students?

iv. How will state and private universities be related? The relations between public and private institutions must be described explicitly; otherwise severe problems may arise in the future.

v. What standards will be applied for election to various teaching and research positions? Will the rules guaranteeing the election of appropriate candidates be valid?

vi. What will be the implications of the new private universities on already existing state universities, and more generally on the teaching and research staff of state universities? If the rules and the general framework of the functioning of private universities are not explicitly decided and written prior to the official beginning of their activities, this might lead to the "disappearance 11 of the smaller, peripheral state universities by the absorption of highly qualified teaching and research staff by the new private universities.

The above questions show how complicated is the problem of the private universities. Establishing private universities should be avoided before the rules and the general framework of their functioning are clearly and explicitly set. 
9. There are serious disadvantages with the system, valid up to now, of entrance examinations to universities and technological institutes. These can seriously affect high-school students participating in the annual examinations. The entire system of entrance examinations is based on merely four examinations in four different subjects. These examinations normally take place in June, and each one takes about three hours. They play a critical role because there are many candidates and the outcome of the four examinations is the sole criterion for the students' success. The situation becomes even more complicated in some schools, such as the medical schools that require a grade of at least 95 percent. Obviously such a system cannot be stable in the long run, because such a school contains only the excellent students. Finally, in taking the introductory examinations, a candidate chooses a number of schools or departments, belonging to a clearly distinct group, and, according to his or her grades, he or she can succeed in them. For example, in the health sciences the group contains the schools of medicine, dentistry, pharmacology and biology, and a student interested in medicine might find himself succeeding in, for example, biology.

In view of the above, a new legislative framework for the university's functioning must guarantee the following:

1. The proper functioning of the various departments and faculties as well as the effectiveness of the administration.

2. The general principles of undergraduate and postgraduate studies that will allow and facilitate the departments to choose the right way of teaching, conducting research, and general functioning.

3. The succession and continuous renewal of the teaching/research staff with emphasis on the recruitment of successful scientists from abroad, in order to improve the level of studies and research. In this respect one might examine the suggestion that voting in the elections be secret in order to exclude sentimental, professional, friendly, and social relations and bonds, and ensure the objectiveness of the electors.

4. The improvement of the odd proportionality in the composition of the teaching/research staff, and the distribution and importance of the various areas of knowledge. Such an improvement could contribute to a renewal of the staff. 
5. The positions of retired professors are not filled. A plan for a period of, say, four years is necessary, during which new positions would be announced automatically and filled. Also, every application for promotion must be considered within the framework of this plan. In this way, new scientists will enter the university, and the number of full professors, which increase as a result of continuous applications for promotion, will be limited in favor of new staff. Also the plan must take into account the needs emerging from the development of science, so that promotions and announcements of new positions can be made according to these new scientific directions. This will reasonably limit the number of professors in the same field and permit the development of new directions in research. Special attention must be given to the creation of incentives for staff members with distinguished scientific productivity; the evaluation of the quality of university services offered; the response of the universities to the needs of their social surroundings; and the decreasing influence of political parties on the universities.

As far as the Internal Regulations are concerned, I believe that it must describe explicitly the rights and obligations of each member of the university community, and also include the penalties in each case for everyone. Of special importance are the specific regulations concerning asylum in the university, in such a way that the university campus be a forum for the free flow of ideas and not the asylum of criminals in the broader sense of the term. The "Internal Regulations" must guarantee the quality of under- and post-graduate studies, and the continuous updating of study programs and teaching methods. Small classes must be supported, because they make for more effective contact between teacher and student, and better evaluation of the students. Also the internalization of the studies, based on the fact that science has no home, will contribute to the convergence of Greek universities with those abroad.

It is important to facilitate the creation of student clubs, so that the nonacademic interests of the students (athletics, arts, and so on) are cultivated together with the purely academic ones. Finally, all available possibilities must be exploited so that undergraduate students, with some financial aid, can help the staff with their teaching duties. 


\section{Conclusion}

Universities need a legislative framework and internal regulations in order to be self-governed in a controllable way. The self-sufficiency of the universities must not isolate them from their social surroundings, and universities must pursue a leading role in addressing the problems of the society. However, one should always keep in mind that, irrespective of any laws and rules, the really successful functioning of the university relies on the mutual respect and acceptance of the staff members in their day-today life. 